\title{
On the hunt for the gene of perspective taking: pitfalls in methodology
}

\author{
Ádám Miklósi • József Topál
}

Published online: 20 July 2011

(C) Psychonomic Society, Inc. 2011

\begin{abstract}
In this commentary, we evaluate the methodology of Udell, Dorey, and Wynne's (Learning \& Behavior, in press) experiment in controlling for environmental factors and argue that their conclusion is not supported. In particular, we emphasise that comparative studies on dogs and wolves need to ensure that both species enjoyed the same rearing history, are comparable in age, and have the same experience with the testing conditions. We also argue that the utilisation of shelter dogs does not control for genetic effects on social behaviour. Finally, we propose a synergetic model to account for both genetic and environmental effects on interspecific social behaviour in dogs and wolves.
\end{abstract}

Keywords Comparative cognition $\cdot$ Dog $\cdot$ Wolf

The study by Udell, Dorey, and Wynne (in press) is the newest piece in a stream of publications investigating and comparing heterospecific communicative skills in dogs and wolves. As the conclusion of their study, the authors echo their main message: "domestication is neither required, nor is it sufficient, to explain" trait X or Y in the dog (see also Udell, Dorey, \& Wynne, 2008).

\footnotetext{
Á. Miklósi $(\bowtie)$

Department of Ethology, Lorand Eötvös University, Pázmány P. s 1c,

Budapest 1117, Hungary

e-mail: amiklosi62@gmail.com

\section{J. Topál}

Comparative Behavioural Research Group, Research Institute for Psychology, Hungarian Academy of Sciences,

Victor Hugo u. 18-22,

Budapest 1132, Hungary
}

As we explain below, there are both theoretical and methodological issues that make the central thesis problematic. First, there is evidence to suggest that domestication is a genetic process, and it has been defined as a genetic accommodation (change in allele frequencies, mutations, etc.) to the anthropogenic environment (Price, 1999), which is supported also by recent genetic analyses (Parker et al., 2004). Even a relatively small-scale long-term experiment that selected for "tame behavior" in foxes produced divergence in the morphological (Belyaev, 1978) and behavioural (Trut, 1999) phenotypes that has been produced by genetic changes (see, e.g., Lindberg et al., 2005). Despite this, we do not know to what extent these genes or any allelic variations contribute to special aspects of behaviour in dogs. Based on the evidence from foxes, it is very likely that social behaviour, including communicative abilities, has been influenced. One could hypothesise that the genome of the dog has undergone many small changes during domestication that have added up and resulted in a markedly changed overall phenotype. Thus, the genetic contribution to any particular trait (measured in an experiment) may be small, and additionally, the effects of genes on such complex epiphenomena as social cognitive skills are likely to manifest through interaction with environmental factors. That is, genes influencing the emergence of cognitive skills in dogs (e.g., "perspective taking") may not do so directly, but rather indirectly, by making individuals more sensitive to the effects of certain environmental factors (e.g., human communicative signals; cf. Gácsi et al., 2009). Therefore, unless we gain better insight into the developmental gene-environment interactions, we cannot answer whether or not domestication played a significant role in the formation of dogs' social cognitive skills. 
For that very reason, it is important to comply with the number one rule in comparative behaviour geneticsthat is, in order to reveal genetic contributions to behaviour, environmental conditions should be kept the same for all individuals included in the experiment. We fulfilled this criterion by applying the same intensive socialisation program to both dog and wolf puppies (Miklósi et al., 2003; Topál et al., 2005), and we found some small, but important, differences that could be attributed to the effect of domestication. Importantly, however, such small (and often interactional) effects can be easily overlooked if one varies environmental influences when comparing dogs to wolves.

In recent years, it has became popular not only to socialise wolves, but also to train them extensively. It is particularly difficult to evaluate the effect of such influence on behaviour, because authors do not provide all details in the Method sections of their articles. Importantly, however, such practice can mask genetic differences if researchers compare dogs from average human households with wolves who are socialised and trained by expert staff.

Unfortunately, Udell et al.'s (in press) study also suffers from this methodological weakness. Dogs and wolves in their study had been reared in very different conditions, and before the experiments at least the majority of their wolves (unlike dogs) were subjected to extensive associative conditioning (clicker training) and were familiarised with two-way object choice situations (see Udell, Dorey, \& Wynne, 2008).

In addition, the large difference in the mean ages of the experimental groups (shelter dogs, pet dogs, wolves) makes the results of the Udell et al. (in press) study difficult to interpret. Namely, the wolves (mean \pm SE: $7.5 \pm$ 1.46 years) were significantly older than the pet dogs $(3.2 \pm$ 0.61 years), which were tested outdoors like the wolves $[t(24)=3.207, p=.0038]$. The shelter dogs $(1.2 \pm 0.17$ years $)$ were also significantly younger than the pet dogs $(2.9 \pm$ 0.5 years) and were tested indoors $[t(31)=3.098, p=.0041]$. Moreover, the majority of the shelter dogs had not reached maturity (were younger then 1 year). (Raw data were obtained from Udell et al., in press, Table 1.)

Systematic variation in age is an important factor because, according to Udell et al.'s (in press) two-stage hypothesis, relevant life experiences is of primary importance, and thus the individual's age should be an important factor affecting task performance. The older an individual is, the more relevant learning experience is supposed to be gained. Thus, using subjects of similar age in the different groups represents an important aspect of the study design.

Moreover, the fact that middle-aged adult wolves (having some task-specific experience) did not perform better than much younger shelter dogs (without any task-specific experience) does not fit well the predictions of the two-stage hypothesis (see Udell et al., in press, Exp. 1). It also seems to contradict Udell et al.'s (in press) hypothesis that half of the task-naive pet dogs (7 out of 14) passed the "perspective-taking" task in the unfamiliar "bucket condition" from the very beginning, while only 1 of 8 wolves (in Exps. 1 and 2) achieved this level of performance, despite of the fact that these animals were not task naive and were significantly older than the dogs.

In summary, the study design does not allow us to draw strong conclusions about the differences between wolves, pet dogs, and shelter dogs. It is not possible to test whether the rearing and living environment of the subject(s) (shelter or human home) or species identity (dog vs. wolf) has a greater impact on an individual's performance unless we (1) standardise the environmental factors, (2) try to keep experiences with relevant stimuli constant across species, and (3) observe and/or test dogs and wolves using exactly the same procedures (Miklósi, 2007).

Thus, we are left with the conclusion that wolves with particular social experience are sensitive to certain manifestations of human attentional state under some conditions, and the dogs' flexibility to detect human visual cues of attention is affected by the age, rearing conditions, and treatment practices.

Interestingly, we may draw a parallel between dogs and human children with regard to the studies comparing "socially deprived" (shelter/orphanage) individuals with typically developed samples (pet dogs/children in families). For example, it has been recently reported that many children who have resided in very deprived institutional environments may exhibit specific deficits in cognitive and social functioning (Rutter et al., 2007). This autistic-type behaviour pattern is an acquired syndrome that may be related to institutionalisation. Thus, the environment can have a significant effect on human social cognition. Note this hypothetical example: Providing evidence that encultured (human-reared) chimpanzees outperform children with institutional autism (e.g., in a task based on the subject's ability to follow human's gaze) should not lead one to conclude that human-specific genetic predispositions, which may have evolved during hominisation, play no role in gaze following behaviour in particular or in the manifestation of other aspects of human social cognition.

In a similar vein, one cannot reject the possibility that a genetic predisposition (domestication effect) exists in the $\operatorname{dog}$ on the basis of the finding that dogs with limited human social experience show often poor spontaneous sensitivity to human signals, while intensely 
trained and socialised wolves perform reliably under certain conditions.

In summary, Udell et al.'s (in press) results provide some support for the notion that a genetic predisposition acquired through domestication is not sufficient to the development of proper sociocognitive skills in dogs, but the experimental design is not adequate to exclude specific dog-wolf differences in their predispositions to learn from human signals. Until the environmental effects are controlled for in such studies, any conclusions about the contribution of domestication (or the lack of it) is premature.

Elsewhere, we have proposed a different approach focusing on the genotype-by-environment interaction (Gácsi et al., 2009; Miklósi \& Topál, in press), a more plausible model of the general effects of domestication that takes into account both genetic and environmental variability in the dog and wolf, as well as the fact that the same developmental endpoint (performance in a particular task) can be achieved through different pathways. This account differs from the linear genephenotype approach by positing a causal role for neither genes nor environment in isolation, but for their synergetic coparticipation in the emergence of social cognitive skills, where the effect of one is conditional on the other.

This synergetic model (Fig. 1) presumes that there was some positive selection for genetic factors during domestication, some of which play a role in sociality (e.g., vonHoldt et al., 2010), especially with respect to



Fig. 1 A simple sketch of the synergetic model on the emergence of interspecific social skills in dogs and wolves (based on Miklósi \& Topál, in press). The model assumes some genetic advantage on the part of the dog for acquiring a range of social skills that are utilised in the human-dog relationships. These social skills emerge after relatively short social experience with humans. Wolves can also develop comparable social skills; however, they need significantly more intensive human social input to approach or achieve the same levels of performance. Lack or intermission of social experience may lead to deteriorated social performance in both species, but this process is faster in wolves heterospecific interactions. This could include preference towards humans, looking at human gaze, and so forth. These changes allow for social experience during development to have markedly different effects on the behaviour of dogs and wolves. The most important aspect of this model is that in dogs, the effects of positive selection (genetic advantages) manifest only in a proper social environment, and even without such selective history, wolves can also reach high levels of interspecific social skills if socialised intensively.

Furthermore, there could have been several points in the development of the two species when, depending on the differential genetic and social environmental contributions, no difference between dogs and wolves would have been observed with regard to social skills. It is important to note that socialisation or social experience should be regarded as maintaining environmental stimulation, in the sense of Caro and Bateson's (1986) model on behavioural development; thus, harmful social experience or intermissions of social experience may disrupt the manifestation of former social skills.

In our view, species-environment interaction seems a particularly suitable approach for understanding the development of social cognition in both dogs and wolves, because this epiphenomenon is known to be associated with environmentally mediated factors, yet individual dogs and wolves display considerable heterogeneity in their response to those environmental exposures. The synergetic model makes several predictions for which there is general support. First, it predicts that dogs need less social experience with humans and less scheduled (i.e., more "ad hoc") social experience with humans than do wolves to achieve the same level of social skills. This is supported by Gácsi et al. (2009), who found that dog puppies show better performance in finding food following an experimenter's cueing, and that this difference disappears later in development, presumably due to the acquisition of increasing amounts of environmental social experience in the wolves. Second, dogs without or with little interspecific social experience show retarded social skills that may be actually inferior to those observed in socialised wolves (Udell, Dorey, \& Wynne, 2010). Third, the model predicts that intensive socialisation, as compared to the "customary" socialisation, will have a smaller performance-improving effect on dogs' social skills in comparison to wolves.

In conclusion, the effects of domestication on the social skills of dogs should be evaluated in a framework of more flexible behavioural models that consider the contributions of genetic and social factors. Only clear-cut hypotheses and experimentally controlled procedures and designs have the potential to find valid answers for comparative behaviour genetics. 


\section{References}

Belyaev, D. K. (1978). Destabilizing selection as a factor in domestication. Journal of Heredity, 70, 301-308.

Caro, T. M., \& Bateson, P. (1986). Organisation and ontogeny of alternative tactics. Animal Behaviour, 34, 1483-1499.

Gácsi, M., Győri, B., Virányi, Z., Kubinyi, E., Range, F., Belényi, B., et al. (2009). Explaining dog wolf differences in utilizing human pointing gestures: Selection for synergistic shifts in the development of some social skills. PloS One, 4. doi:10.1371/journal.pone.0006584.

Lindberg, J., Björnerfeldt, S., Saetre, P., Svartberg, K., Seehuus, B., Bakken, M., et al. (2005). Supplemental data: Selection for tameness has changed brain gene expression in silver foxes. Current Biology, 15, 915-916.

Miklósi, Á. (2007). Dog behaviour, evolution, and cognition. Oxford: Oxford University Press.

Miklósi, Á., Kubinyi, E., Topál, J., Gácsi, M., Virányi, Z., \& Csányi, V. (2003). A simple reason for a big difference wolves do not look back at humans, but dogs do. Current Biology, 13, 763-766.

Miklósi, Á., \& Topál, J. (in press). The evolution of canine cognition. In J. Vonk \& T. Shackelford (Eds.), The Oxford handbook of comparative evolutionary psychology. Oxford: Oxford University Press.

Parker, H. G., Kim, L. V., Sutter, N. B., Carlson, S., Lorentzen, T. D., Malek, T. B., et al. (2004). Genetic structure of the purebred domestic dog. Science, 304, 1160-1164.

Price, E. O. (1999). Behavioural development in animals undergoing domestication. Applied Animal Behaviour Science, 65, 245-271.

Rutter, M., Kreppner, J., Croft, C., Murin, M., Colvert, E., Beckett, C., et al. (2007). Early adolescent outcomes of institutionally deprived and non-deprived adoptees: III. Quasi-autism. Journal of Child Psychology and Psychiatry, 48, 1200-1207.

Topál, J., Gácsi, M., Miklósi, Á., Virányi, Z., Kubinyi, E., \& Csányi, V. (2005). The effect of domestication and socialization on attachment to human: A comparative study on hand reared wolves and differently socialized dog puppies. Animal Behaviour, 70, 1367-1375.

Trut, L. (1999). Early canid domestication: The farm-fox experiment. American Scientist, 87, 160-169.

Udell, M. A. R., Dorey, N. R., \& Wynne, C. D. L. (2008). Wolves outperform dogs in following human social cues. Animal Behaviour, 76, 1767-1773. doi:10.1016/j.anbehav.2008.07.028.

Udell, M. A. R., Dorey, N. R., \& Wynne, C. D. L. (2010). What did domestication do to dogs? A new account of dogs' sensitivity to human actions. Biological Reviews, 85, 327-345.

Udell, M. A. R., Dorey, N. R., \& Wynne, C. D. L. (in press). Can your dog read your mind? Understanding the causes of canine perspective taking. Learning \& Behavior. doi:10.3758/s13420011-0034-6

vonHoldt, B. M., Pollinger, J. P., Lohnmüller, K. E., Han, E., Parker, H. G., Quignon, P., et al. (2010). Genome-wide SNP and haplotype analyses reveal a rich history underlying dog domestication. Nature, 464, 898-902.

\section{Author note}

This work was funded by the Hungarian Science Foundation (OTKA 308 K76043), by the ESF Research Networking Program "COMPCOG" and by the European Union (EU FP7 ICT-215554 LIREC). 